\title{
Effect of self-assembled peptide-mesenchymal stem cell complex on the progression of osteoarthritis in a rat model
}

This article was published in the following Dove Press journal:

International Journal of Nanomedicine

7 May 2014

Number of times this article has been viewed

\section{Ji Eun Kim' \\ Sang Mok Lee ${ }^{2}$ \\ Soo Hyun Kim' \\ Phil Tatman ${ }^{3}$ \\ Albert $\mathrm{O} \mathrm{Gee}{ }^{4}$ \\ Deok-Ho Kim ${ }^{3,5}$ \\ Kyung Eun Lee ${ }^{6}$ \\ Youngmee Jung' \\ Sang Jun $\mathrm{Kim}^{2}$}

'Biomaterials Research Center, Korea Institute of Science and Technology, Seoul, South Korea; ${ }^{2}$ Department of Physical and Rehabilitation Medicine, Samsung Medical Center, Seoul, South Korea; ${ }^{3}$ Department of Bioengineering, ${ }^{4}$ Department of Orthopaedics and Sports Medicine, ${ }^{5}$ Institute for Stem Cell and Regenerative Medicine and Center for Cardiovascular Biology, University of Washington, Seattle, WA, USA; ${ }^{6}$ Advanced Analysis Center, Korea Institute of Science and Technology, Seoul, South Korea

Correspondence: Sang Jun Kim Department of Physical and Rehabilitation Medicine, Samsung Medical Center,

8I Irwon-Ro Gangnam-gu,

Seoul I35-710, South Korea

$\mathrm{Tel}+82234106069$

Fax +82 234100057

Email guitarren.kim@samsung.com

Youngmee Jung

Biomaterials Research Center,

Korea Institute of Science and

Technology, | 3 | Cheongryang,

Seoul, Jongrogu, Republic of Korea

Tel +82 29585343

Fax +8229585308

Email winnie97@kist.re.kr
Purpose: To evaluate the efficacy of mesenchymal stem cells (MSCs) encapsulated in selfassembled peptide (SAP) hydrogels in a rat knee model for the prevention of osteoarthritis (OA) progression.

Materials and methods: Nanostructured KLD-12 SAPs were used as the injectable hydrogels. Thirty-three Sprague Dawley rats were used for the OA model. Ten rats were used for the evaluation of biotin-tagged SAP disappearance. Twenty-three rats were divided into four groups: MSC ( $n=6)$, SAP ( $n=6)$, SAP-MSC $(n=6)$, and no treatment $(n=5)$. MSCs, SAPs, and SAP-MSCs were injected into the knee joints 3 weeks postsurgery. Histologic examination, immunofluorescent staining, measurement of cytokine levels, and micro-computed tomography analysis were conducted 6 weeks after injections. Behavioral studies were done to establish baseline measurements before treatment, and repeated 3 and 6 weeks after treatment to measure the efficacy of SAP-MSCs.

Results: Concentration of biotinylated SAP at week 1 was not significantly different from those at week 3 and week $6(P=0.565)$. Bone mineral density was significantly lower in SAP-MSC groups than controls $(P=0.002)$. Significant differences in terminal deoxynucleotidyl transferase deoxyuridine triphosphate nick-end labeling staining between the control group and all other groups were observed. Caspase-8, tissue inhibitor of metalloproteinases 1, and matrix metalloproteinase 9 were diffusely stained in controls, whereas localized or minimal staining was observed in other groups. Modified Mankin scores were significantly lower in the SAP and SAP-MSC groups than in controls $(P=0.001$ and 0.013$)$. Although not statistically significant, synovial inflammation scores were lower in the SAP (1.3 \pm 0.3$)$ and SAP-MSC (1.3 \pm 0.2$)$ groups than in controls $(2.6 \pm 0.2)$. However, neither the cytokine level nor the behavioral score was significantly different between groups.

Conclusion: Injection of SAP-MSC hydrogels showed evidence of chondroprotection, as measured by the histologic grading and decreased expression of biochemical markers of inflammation and apoptosis. It also lowered subchondral bone mineral density, which can be increased by OA. This suggests that the SAP-MSC complex may have clinical potential to inhibit OA progression.

Keywords: self-assembled peptide, mesenchymal stem cell, osteoarthritis, apoptosis, chondrogenesis

\section{Introduction}

Osteoarthritis (OA), or degenerative arthritis, is a progressive musculoskeletal condition that involves the deterioration of articular cartilage and subsequent subchondral bone erosion. ${ }^{1}$ Although the exact pathophysiology of the condition has not been uncovered yet, it is generally considered to be caused by a combination of cumulative 
mechanical stresses from aging, destructive biochemical changes taking place in the synovial membrane, and apoptosis of chondrocytes..$^{2-5}$ Clinically, there are several classes of treatments for OA, including nonpharmacological, pharmacological, and surgical treatment modalities. However, these treatments provide largely symptom relief, and do not halt the progression of the disease.

There have been many trials to halt or delay the progression of OA using injected materials. They have focused on the inhibition of the inflammatory process caused by OA. ${ }^{6,7}$ The inflammatory changes are known to be mediated by multiple cytokines. ${ }^{7}$ However, recent research about OA pathophysiology suggested more complicated unknown processes in relation to the progression of OA, not simply the inflammatory process. ${ }^{8}$ In a recent review, ${ }^{5}$ the authors suggested that chondrocyte apoptosis occurs in osteoarthritic cartilage, and autophagy may play a role in determining this cellular apoptosis. Recent trials to delay the progression of OA have focused on the inhibition of this chondrocyte apoptosis. $^{9}$

Research on the use of mesenchymal stem cells (MSCs) for cartilage repair in OA has shown favorable effects of MSCs on cartilage repair. ${ }^{10,11}$ The anti-inflammatory and immunomodulatory properties of MSCs are encouraging features that have driven research in this area toward potential clinical application. ${ }^{12}$ However, only one in vitro study ${ }^{9}$ has investigated the use of MSCs in relation to a reduction of apoptosis in OA models.

Direct application of MSCs into the articular cavity through open surgery represents a substantial morbidity for patients with OA. Therefore, intra-articular injection of MSCs is an attractive mode of introducing MSC-based therapies for OA in the clinical setting. However, successful intra-articular administration of MSCs requires appropriate biocompatible scaffolds to enhance the chondrogenesis of MSCs and to increase the half-life of MSCs after administration. ${ }^{6}$ Another requirement of any clinically applicable scaffold is biocompatibility of the material, as foreign materials injected into the joint are degraded by the host immune system.

Self-assembled peptide (SAP) is a versatile biomaterial that is typically composed of alternating hydrophilic and hydrophobic side groups, allowing self-assembly into ordered nanostructures that occurs either spontaneously or in response to an exogenous stimulus. ${ }^{13,14}$ The injectable peptides are organized as 5-10 nm fibers, and assemble into a three-dimensional scaffold at suitable physiological $\mathrm{pH}$ and osmolality to form a hydrogel. ${ }^{15,16} \mathrm{SAP}$ is also biodegradable, easily processed in vivo by various proteases, and has superior biocompatibility within the native tissue since the degradation products of SAP are natural amino acids.

Additionally, SAP has versatility in its functionality by incorporating specific cellular motifs based on desired function. ${ }^{17,18}$ Recent studies have shown that hydrogels made of the SAP sequences RADA-16 and KLD-12 can maintain the chondrocyte phenotype ${ }^{19}$ and stimulate chondrogenesis of bone marrow stromal cells in vitro. ${ }^{20-22}$ Miller et $\mathrm{al}^{23}$ reported markedly improved cartilage regeneration from using KLD-12, known to form a stable $\beta$-sheet in fullthickness articular cartilage defects. The study showed that KLD-12 can promote cartilage regeneration without inducing a significant immune response, thus emphasizing its use as a potential scaffold for $\mathrm{OA}$.

Therefore, the successful development of an SAP hydrogel scaffold, which promotes appropriate articular tissue response and provides the proper microenvironment for MSC differentiation, would notably facilitate the application of MSCs for therapeutic treatment of OA. In the present study, we induced OA in a rat knee model, administered intraarticular injections of MSCs encapsulated in prepared SAP with a sequence of Ac-KLDLKLDLKLDL-NH2 (KLD-12), and conducted behavioral and histological analysis on the OA-induced animals. In addition, we measured the rate of disappearance from the articular cavity using the biotinylated KLD-12. In doing so, we examined the residence period of the SAP-MSC composites on OA in a rat model and determined the applicability of the KLD-12 SAP hydrogel as a scaffold. We hypothesized that the SAP-MSC composites would reduce the rate of cartilage destruction and apoptosis, thus halting the progression of OA and positively affecting joint function.

\section{Materials and methods}

A total of 38 female Sprague Dawley (SD) rats were used for this study. Five 5-week-old female SD rats were used for bone marrow mesenchymal stem cell isolation. Twenty-three female 12-week-old SD rats weighing between 275 and $350 \mathrm{~g}$ at the beginning of the study period were used for testing the efficacy of treatments. An additional ten 12-week-old $\mathrm{SD}$ rats were used for estimating the rate of disappearance of injected compounds. All rats were kept in cages located in an air-conditioned room, while commercial pellet and tap water were provided ad libitum. A week of acclimation was allowed prior to the start of the experiment.

All experimental procedures were performed in accordance with standard operating protocols established by 
the Institutional Animal Care and Use Committee at our Biomedical Research Institute. All protocols in this study were approved by the Institutional Review Board of Animal Experiments at our institutes.

\section{Bone marrow mesenchymal stem cell isolation and culture}

The cells were isolated using a modified protocol that has been previously described. ${ }^{24}$ Rat bone marrow stromal cells (rBMSCs) were isolated from the femur and tibia of SD rats ( 5 weeks old). Femur and tibia from both knees were isolated with sterile forceps and surgical scissors, and both ends of the long bones were cut away. The medullary cavity of remaining diaphysis was washed with phosphate-buffered saline (PBS; Corning Cellgro $^{\circledR}$, Corning, NY, USA) via syringe. Bone marrow with PBS was obtained by collecting the washings. Mononuclear cells from the bone marrow were isolated from PBS by Ficoll-Hypaque density-gradient centrifugation for 20 minutes at 1,500 rpm. The collected mononuclear cells were plated into culture flasks (Nunc; Thermo Fisher Scientific, Waltham, MA, USA) and cultured in Dulbecco's modified Eagle's medium/Nutrient Mixture Ham-12 (Corning) containing 10\% fetal bovine serum (Corning) and 100 units $/ \mathrm{mL}$ penicillin and $0.1 \mathrm{mg} / \mathrm{mL}$ streptomycin (Corning) at $37^{\circ} \mathrm{C}$ in a humidified atmosphere containing $5 \% \mathrm{CO}_{2}$. $\mathrm{rBMSCs}$ that had undergone three passages were used in this study.

\section{KLD-I 2 self-assembling peptide hydrogel preparation}

The KLD-12 SAP (Peptron, Daejeon, South Korea) was synthesized and dissolved in $295 \mathrm{mM}$ sucrose solution to produce $1 \%$ KLD-12 peptide gel. The solution was then mixed with PBS and sonicated with an ultrasonic cleanser for 30 minutes to prepare $0.5 \%$ KLD-12 hydrogel. The detailed methods have been described previously. ${ }^{25}$ To identify the structure of KLD-12 SAP, transmission electron microscopy (TEM) was used. Peptide samples were diluted in distilled water to a working concentration of $0.01 \%$. After staining with $2 \%$ uranyl acetate, TEM images were acquired (CM30; Philips, Amsterdam, Netherlands) (Figure 1).

\section{Surgical induction of osteoarthritis}

For the OA model, 33 rats were anesthetized with an intraperitoneal injection of a 1:1 mixture of tiletamine and zolazepam (Zoletil 50; Virbac, Carros, France) with xylazine (Rompun; Bayer, Leverkusen, Germany) at a dose of $30 \mathrm{mg}$ Zoletil and $10 \mathrm{mg}$ Rompun per kilogram of body weight. The anterior surface of the left hind limb was shaved with

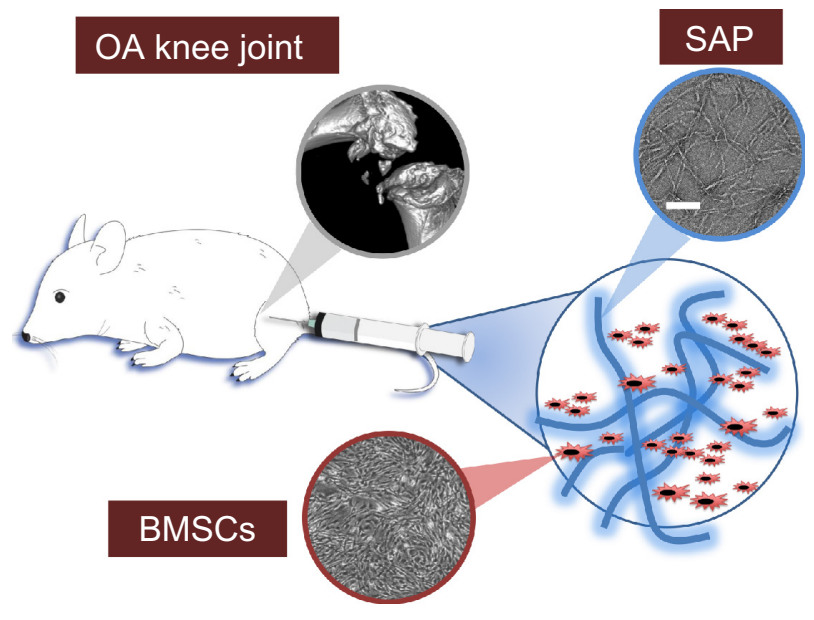

Figure I Bone marrow-derived mesenchymal stem cells (BMSCs) encapsulated in self-assembled peptide (SAP) were injected directly into the articular cavity of osteoarthritis (OA) knee joints. SAP is characterized by the formation of networks of peptide $\beta$-sheet filaments. Scale bar $50 \mathrm{~nm}$.

an electric clipper, and the skin around the incision area was cleansed with Betadine. The skin and fascia on the kneecap region of the left hind limb was vertically incised in the midline for a distance of approximately $4 \mathrm{~cm}$. The patella was retracted laterally to expose the articular cavity. The synovial membrane was excised, and the knee joint was bent to expose the anterior cruciate ligament. The medial collateral ligament was also exposed by retracting the pes anserine muscles aside. Then, the anterior cruciate and medial collateral ligaments were transected, and the medial meniscus was completely removed with surgical scissors. The patella was then relocated back to its original position, and the fascia and skin were closed with $3-0$ polydioxanone suture. A single dose of antibiotic cream was applied to prevent postoperative infection.

\section{In vivo SAP disappearance analysis}

SAP was tagged with biotin as a molecular tag by chemical bonding (Peptron). Biotinylated SAP was dissolved in $295 \mathrm{mM}$ sucrose solution to produce 1\% peptide gel. The solution was then mixed with PBS and sonicated with an ultrasonic cleanser for 30 minutes to prepare $0.5 \%$ peptide gel. The unbound peptides were removed through extensive washing in accordance with a previously reported protocol. ${ }^{26}$ Ten rats were surgically induced to develop OA. The prepared biotinylated SAP $(0.2 \mathrm{~mL})$ was injected 3 weeks after the surgery.

At 1, 3, and 6 weeks after the injection, synovial fluid was washed with PBS using a syringe while being extracted with another syringe (as described in the "Cytokine concentration" section). To estimate biotin-labeled incorporation, 
synovial fluid containing the labeled biotin was added to a mixture of 4-hydroxyazobenzene-2-carboxylic acid and avidin (Thermo Fisher Scientific). The resulting solution was added to 96-well plates, and the plates were examined using a microplate reader. The absorbance was measured at $500 \mathrm{~nm}$.

In addition, the disappearance rate of biotinylated SAP was detected by DyLight 594-conjugated streptavidin (Thermo Fisher Scientific) staining. In each group, two rats were killed at week 1 , four rats at week 3 , four rats at week 6 . Nuclei were counterstained with 4',6-diamidino-2-phenylindole (DAPI; Life Technologies, Carlsbad, CA, USA), and the samples were examined using fluorescence microscopy (Eclipse TE2000U; Nikon, Tokyo, Japan).

\section{Injection of MSCs encapsulated in KLD- 12 SAP hydrogel}

For the therapeutic efficacy of SAP-MSC, 23 rats were randomly allocated into four groups according to the treatment method, as follows: group 1 was given an SAP injection $(n=6)$; group 2 was given an MSC injection ( $n=6)$; group 3 was given an SAP-MSC injection ( $n=6)$; and group 4 served as a control group and was not given any injection $(n=5)$. For groups 2 and 3, the cultured rBMSCs were collected by trypsin (Corning) treatment and then resuspended in culture media. The injected concentration of rBMSCs was about $1 \times 10^{6}$ cells $/ \mathrm{mL}$. Then, the same volume of cell suspension was mixed with $1 \%$ peptide gel to make a final concentration of $0.5 \%$ peptide gel before injection into the joint. After palpating the patella with the knee bent, a 26-gauge needle was inserted approximately $5 \mathrm{~mm}$ above the upper margin of the patella (Figure S1). With verification of no soft-tissue swelling, $0.2 \mathrm{~mL}$ of each compound was injected directly into the articular cavity. Each injection was administered 3 weeks after the surgical induction of OA.

\section{Cytokine concentration in synovial fluid}

At 6 weeks after the injection, we modified the method described in a previous study to acquire synovial fluid. ${ }^{27}$ An empty syringe and a syringe filled with $0.5 \mathrm{~mL}$ of PBS were prepared. The needles of both syringes were inserted into the articular cavity. PBS was infused into the articular cavity and constantly withdrawn at the same time. A diagram of this technique and a detailed description are presented in the Figure S2. The collected samples were analyzed with a Milliplex ${ }^{\circledR}$ MAP magnetic bead-based rat cytokine/chemokine panel (Millipore, Billerica, MA, USA). Concentrations of interleukin (IL)-1 $\beta$ and tumor necrosis factor (TNF)- $\alpha$ were measured to evaluate the proinflammatory effect of each treatment, and IL-4 was measured for the anti-inflammatory effect. The tests were run twice per sample, and the average values of those measurements were recorded at an outside lab with a specialty in cytokine biochemical analysis (Koma Biotech, Daejeon, South Korea).

\section{Micro-CT analysis}

Six weeks after the injection, 23 rats were killed with a 9:1 mixture of ketamine and Rompun $(5 \mathrm{~mL} / \mathrm{kg})$. The hind limbs of the dead rats were dissected and immediately fixed in formalin 6 weeks after the injection. Samples were imaged using a micro-computed tomography (CT) scanner. We used a scanning time of 0.21 seconds, with settings of $80 \mathrm{kVp}, 500 \mu \mathrm{A}$, and 30 calibrations. Axial and transaxial fields of view of $30.74 \mathrm{~mm}$ were acquired. Bone mineral density was calculated at the lateral femoral condyle area of each sample. A semiquantitative method using the degree of osteophytes and joint destruction was introduced to grade the degree of OA changes (Figure S3). This method has been described in a previous study ${ }^{28}$ in terms of quantification of the degree of cartilage loss and osteophytes, but did not include the subchondral sclerosis and cysts in our study, which was different from the previous study. ${ }^{28}$

\section{Histological and immunofluorescent analysis}

The histological analysis of knee joints in 23 rats was performed 6 weeks after the injection, as described by Appleton et al. ${ }^{29}$ The collected tissue samples were fixed in $10 \%(\mathrm{w} / \mathrm{v})$ buffered formalin, decalcified by hydrogen chloride ethylenediaminetetraacetic acid solution, and embedded in paraffin and then sectioned in the sagittal plane under the midline at $6 \mu \mathrm{m}$ thickness. Collagen was stained using Masson's trichrome, and sulfated glycosaminoglycan was stained with Alcian blue. To observe the nucleus and cytoplasm, we also conducted hematoxylin and eosin staining. Light microscopic photographs of stained slides were taken.

A modified Mankin scoring system was used to evaluate the degree of degeneration. The components for evaluation included 1) cartilage structure (0-6), 2) cartilage cells (0-3), 3) Alcian blue staining ( $0-4)$, and 4) tidemark integrity (0-1). This was referenced from a previous article. ${ }^{30}$

Synovial inflammation was scored based on the synovial lining and cellularity, as described in a previous study. ${ }^{31}$ The synovial inflammation score is 0 when the lining cell layer is one or two cells thick, 1 when three to five cells thick, 2 when six to eight cells thick, and 3 over nine cells thick and/or severe increase in cellularity. 
Matrix metalloproteinase (MMP)-9, caspase-8, tissue inhibitor of metalloproteinases (TIMP)-1, and collagen type II (Santa Cruz Biotechnology, Dallas, TX, USA) were detected by immunofluorescence staining. Alexa Fluor 488 goat antimouse immunoglobulin (Ig)-G, Alexa Fluor 594 rabbit antimouse $\mathrm{IgG}$, Alexa Fluor 488 chicken antigoat $\mathrm{IgG}$, and Alexa Fluor 594 donkey antirabbit IgG (Life Technologies) were used for secondary antibodies. Nuclei were also counterstained with DAPI, and the stained tissues were examined using fluorescence microscopy (Eclipse TE2000U).

\section{TUNEL assay}

Apoptosis of chondrocytes in three rats from each group was detected by the DeadEnd ${ }^{\mathrm{TM}}$ fluorometric terminal deoxynucleotidyl transferase deoxyuridine triphosphate nick-end labeling (TUNEL) system (Promega, Madison, WI, USA) at week 6 after the injection and observed by fluorescent microscopy (Eclipse TE2000U). To identify the apoptosis ratio of cells, we counted the total number of nuclei and the number of TUNEL-positive nuclei in three fields at $200 \times$ magnification with a blinded rater in the border zone. TUNEL-positive cell density (\%) was expressed as the ratio of TUNEL-positive nuclei to the total number of nuclei.

\section{Behavioral analysis}

The following tests were conducted immediately before the injection, and 3 and 6 weeks after the injection.

\section{Number of rears}

An open-field acrylic box with dimensions of $30 \times 30 \times 30 \mathrm{~cm}^{3}$ was placed in a room with minimum noise. The floor of the box was covered with foam stamp pads, and the four sides were covered with white paper. Individual rats were placed in the box and left there for 30 minutes. The rats got their paws stained with ink from a foam stamp pad and left footprints on the paper when they stood on their hind limbs and touched the walls of the box with their forelimbs (Figure S4). The papers with footprints were collected after the test and scanned. The scanned images were analyzed with a medical imaging software program (ImageJ version 1.45; National Institutes of Health, Bethesda, MD, USA). The number of distinct particles above $5 \mathrm{~cm}$ from the bottom of the paper was counted by the software. The number of rears was estimated by dividing the number of particles by 14 , which was derived from the fact that there were seven distinguishable particles found per footprint and two footprints per rear. This method is similar to the method used in a previous study, ${ }^{32}$ and the details are described in Figures S5 and S6.

\section{Maximum stride length}

An open-field acrylic tunnel with dimensions of $30 \times$ $30 \times 100 \mathrm{~cm}^{3}$ was prepared. The floor of the box was covered with a series of white papers. Both ends of the tunnel were temporarily closed off by acrylic plate, and an entry was made by removing the plate covering one end. Individual rats got their paws dipped in ink, and were placed in the tunnel and observed for 30 seconds. The distance from each footprint was manually compared, and the largest stride length was selected for the individual data.

\section{Statistical analysis}

Statistical analysis was performed using SPSS 20.0 (IBM, Armonk, NY, USA) in order to evaluate the correlation between the various treatments and the experimental results. In order to statistically evaluate the data from behavioral analysis, repeated-measures analysis of variance (ANOVA) was conducted to determine whether there were significant differences between treatment groups and different time points. For other experiments, $\chi^{2}$, Kruskal-Wallis, and post hoc Mann-Whitney $U$ tests with Bonferroni correction were also used to determine the differences between groups. The threshold value for statistical significance was set at $P<0.05$.

\section{Results}

To investigate peptide disappearance in the synovial joint, biotinylated SAP concentration was quantitatively analyzed. As shown in Figure 2, the concentration of biotinylated SAP was $3.39 \mathrm{nM} / \mathrm{mL}$ in the SAP group at week 1 , which decreased to $2.55 \mathrm{nM} / \mathrm{mL}$ at week 3 and $2.57 \mathrm{nM} / \mathrm{mL}$ at week 6 . These values showed no significant difference ( $P=0.565$ in Kruskal-Wallis test), which indicated that SAP remained in the synovial joint until 6 weeks.

The concentration of IL- $1 \beta$ in the joint fluid was $1.22 \pm 0.74$ (mean \pm standard error of mean) $\mathrm{ng} / \mathrm{mL}$ in the control group, $1.47 \pm 1.15 \mathrm{ng} / \mathrm{mL}$ in the MSC group, $0.15 \pm 0.11 \mathrm{ng} / \mathrm{mL}$ in the SAP group, and $1.59 \pm 0.61 \mathrm{ng} / \mathrm{mL}$ in the SAP-MSC group. The SAP group showed the lowest concentration of IL-1 $\beta$, although the difference was not significant $(P=0.135)$. TNF- $\alpha$ and IL-4 could not be evaluated any more, because they were lower than $0.01 \mathrm{ng} / \mathrm{mL}$ in all groups, which was below the level of the acceptable error range.

Five rats showed grade $4 \mathrm{OA}$ change, seven rats showed grade 3 , three rats showed grade 2 , and one rat showed grade 1 in micro-CT images (Table 1). No difference between groups was found $(P=0.783)$. The bone mineral densities were $1,067.0 \pm 12.2$ in the control group, $990.2 \pm 13.7$ in the MSC 

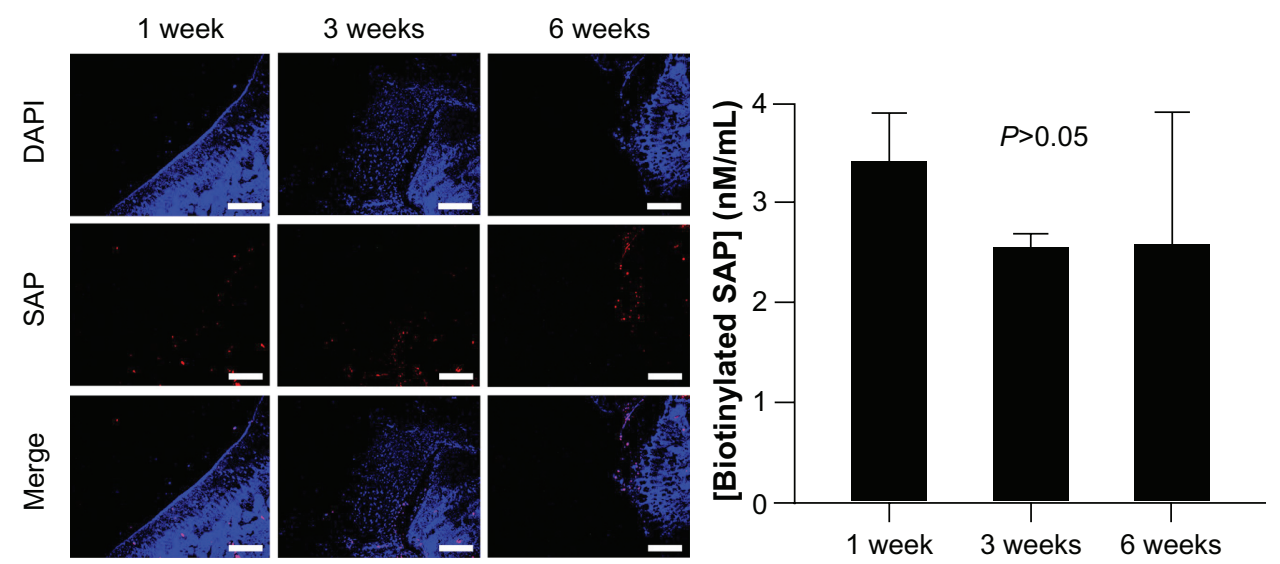

Figure 2 Disappearance rate of biotinylated self-assembled peptides (SAPs) was detected by DyLight 594-conjugated streptavidin staining. Biotinylated SAPs decreased over time but still remained at week 6 . The concentration of biotinylated SAPs at week I $(n=2)$ was not significantly different from those at week 3 ( $n=4)$ and week $6(n=4)$. Scale bar $100 \mu \mathrm{m}$

Abbreviation: DAPI, 4',6-diamidino-2-phenylindole.

group, 1,033.3 \pm 17.4 in the SAP group, and $979.4 \pm 2.9$ in the SAP-MSC group. Kruskal-Wallis and post hoc Bonferroni correction tests showed a significant difference between the control and SAP-MSC groups (corrected $P=0.002$ ). All the micro-CT findings are presented in Figure $S 7$.

In the immunofluorescence assay, diffuse positive staining for caspase- 8 and TIMP-1 were found in the control group, whereas localized or minimal staining was observed in other groups (Figure 3). MMP-9 was diffusely stained in the control group but not in the SAP and SAP-MSC groups (Figure 4). Collagen type II detected by immunofluorescence staining was less abundant in the control group compared to the normal and MSC groups (Figure 4).

TUNEL assay revealed that $35.5 \%$ of chondrocytes in cartilage underwent apoptosis in the negative control group, while only $14.1 \%$ in the MSC group, $9.0 \%$ in the SAP group, and $7.0 \%$ in the SAP-MSC group underwent apoptosis. Significant differences between the control group and other groups were found in Kruskal-Wallis $(P=0.012)$ and post hoc Bonferroni correction tests (Figure 5).

Modified Mankin scores acquired from histologic findings were $11.0 \pm 0.9$ in the control group, $7.0 \pm 0.4$ in the

Table I Group distribution of osteoarthritic changes in microcomputed tomography

\begin{tabular}{lllll}
\hline Group & \multicolumn{4}{l}{ Number of animals in each osteoarthritis grade } \\
\cline { 2 - 5 } & Grade I & Grade 2 & Grade 3 & Grade 4 \\
\hline Control & 0 & 2 & $\mathrm{I}$ & $\mathrm{I}$ \\
MSC & 0 & 0 & 3 & $\mathrm{I}$ \\
SAP & $\mathrm{I}$ & 0 & 2 & $\mathrm{I}$ \\
SAP-MSC & 0 & $\mathrm{I}$ & $\mathrm{I}$ & 2 \\
\hline
\end{tabular}

Abbreviations: MSC, mesenchymal stem cell; SAP, self-assembled peptide.
MSC group, $4.0 \pm 0.8$ in the SAP group, and $5.0 \pm 1.5$ in the SAP-MSC group (Figure 6). The scores in the SAP and SAP-MSC groups were significantly lower than the negative control group. The Kruskal-Wallis score was significant for each group $(P<0.05)$, while the adjusted post hoc $P$-values for the SAP and SAP-MSC groups compared to the control group were reported as 0.001 and 0.013 . However, there was no significant difference in modified Mankin scores between the SAP and SAP-MSC groups or between the control and MSC groups.

Synovial inflammation scores were $2.6 \pm 0.2$ in the control group, $1.8 \pm 0.5$ in the MSC group, $1.3 \pm 0.3$ in the SAP group, and $1.3 \pm 0.2$ in the SAP-MSC group, and were not significantly different $(P>0.05)$ (Figure 7).

The number of attempted rears increased 3 weeks after the injection in all groups except the negative control group. However, 6 weeks after the injection, all groups returned to their initial level of activity, except the MSC group, which surpassed this activity level. The SAP-MSC and MSC groups showed an increased maximum stride length 6 weeks after the injection, while other groups showed a decrease of maximum stride length (Figure 8). Repeated-measures ANOVA testing revealed that there was no significant temporal change in either the number of attempted rears $(F=3.661$, $d f=2, P=0.071)$ or maximum stride length $(F=0.395, d f=2$, $P=0.537)$. There was no difference between the groups in the number of attempted rears $(F=1.246, d f=3, P=0.321)$ or maximum stride length $(F=1.762, d f=3, P=0.188)$.

\section{Discussion}

From this study, we found that the modified Mankin scores were lower in the SAP and SAP-MSC groups compared 


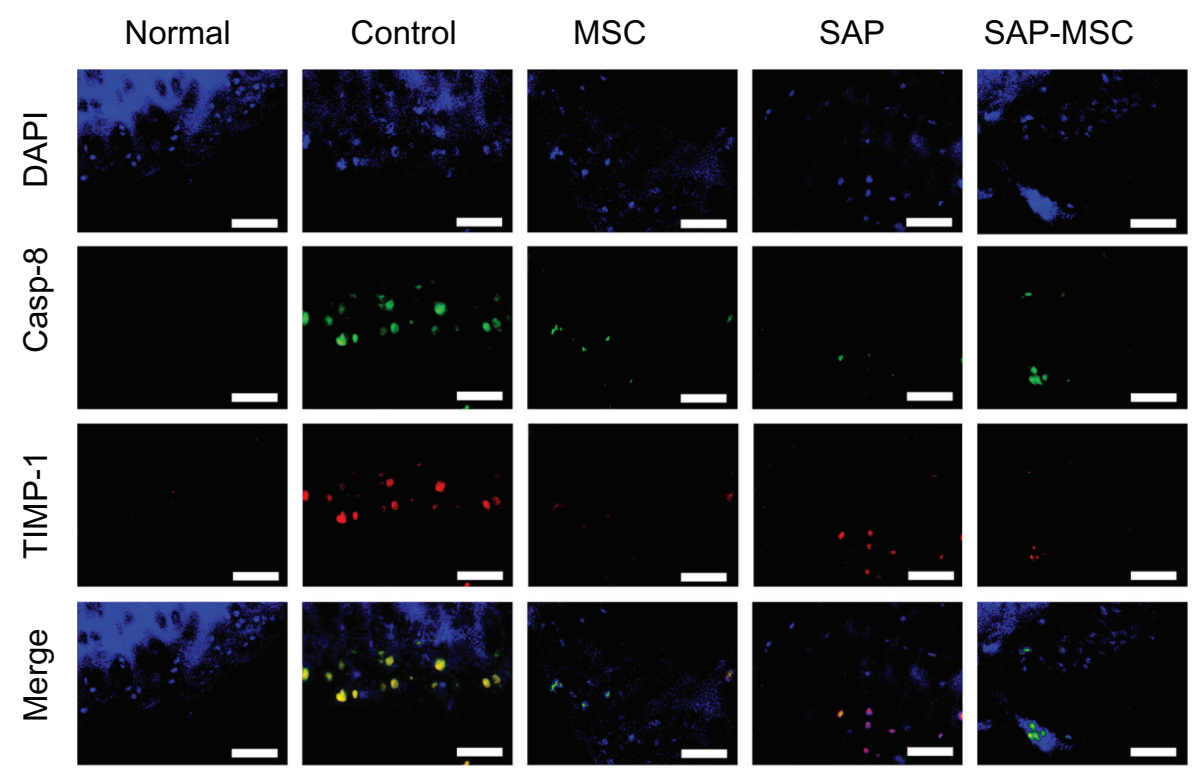

Figure 3 Casp-8 and TIMP-I were detected by immunofluorescence staining. Diffuse positive staining for Casp-8 and TIMP-I were found in the control group, whereas localized or minimal staining was observed in other groups. Scale bar $100 \mu \mathrm{m}$.

Abbreviations: Casp, caspase; TIMP, tissue inhibitor of metalloproteinases; DAPI, 4',6-diamidino-2-phenylindole; MSC, mesenchymal stem cell; SAP, self-assembled peptide.

to the negative control group. This indicates that SAP and SAP-MSC treatment may have had a role in decelerating the progression of $\mathrm{OA}$ in our animal models. This appears to be partly due to the protective effect of SAP and MSC from chondrocyte apoptosis and their curb of the abnormal increase of subchondral bone mineral density caused by OA.

In our results, the SAP and SAP-MSC groups showed better histologic findings than the negative control group, which suggests that SAP by itself plays a functional role in the delay of OA progression. When we separately analyzed for proteoglycan content on the modified Mankin scoring system, we showed improved Alcian blue staining in the SAP $(0.5 \pm 0.3)$ and SAP-MSC $(1.5 \pm 0.3)$ groups versus the negative control group $(2.5 \pm 0.3)$. We postulate that this may be one component of SAP function that is achieved through increasing chondrocyte proteoglycan synthesis.

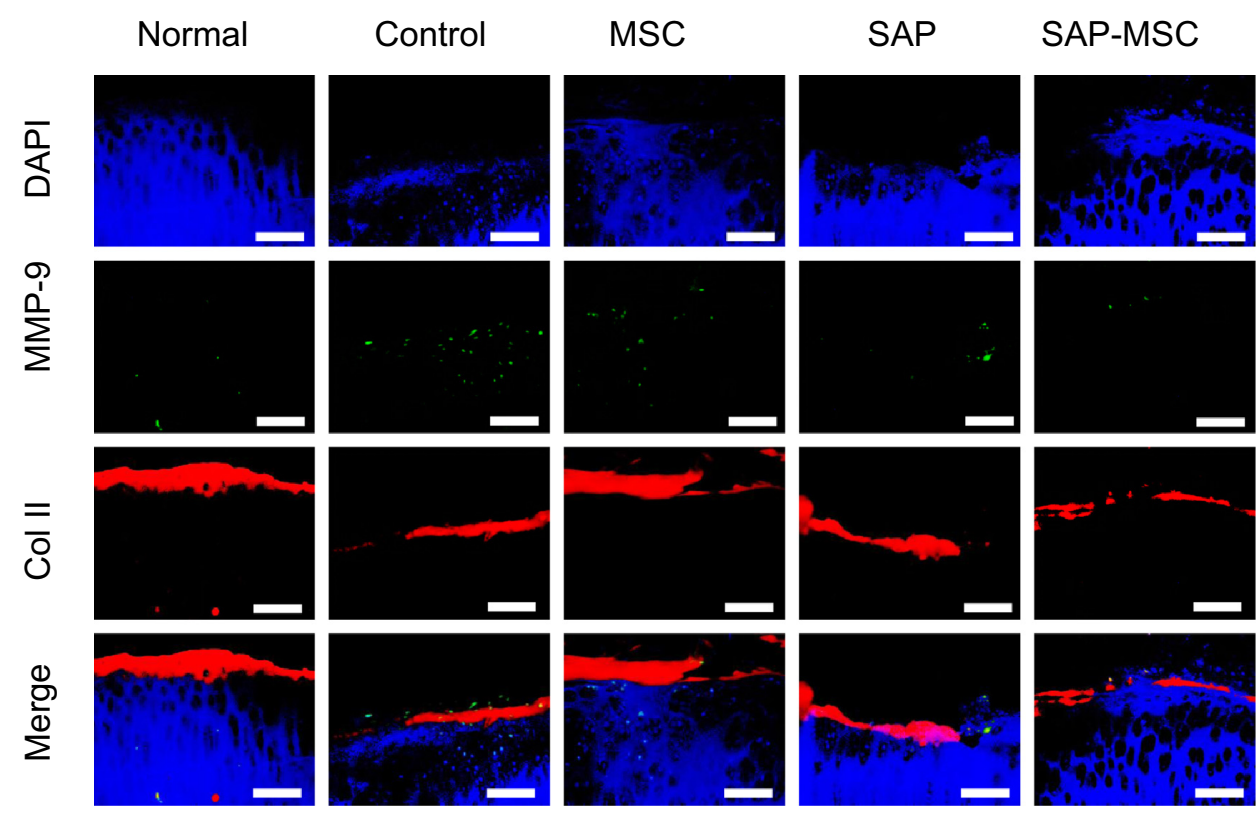

Figure 4 MMP-9 and Col II were detected by immunofluorescence staining. MMP-9 was diffusely stained in the control group, but not in the SAP and SAP-MSC groups. The Col II detected by immunofluorescence staining was less abundant in the control group compared to the normal and MSC groups. Scale bar I00 $\mu$ m.

Abbreviations: MMP, matrix metalloproteinase; Col II, collagen type II; DAPI, 4',6-diamidino-2-phenylindole; MSC, mesenchymal stem cell; SAP, self-assembled peptide. 


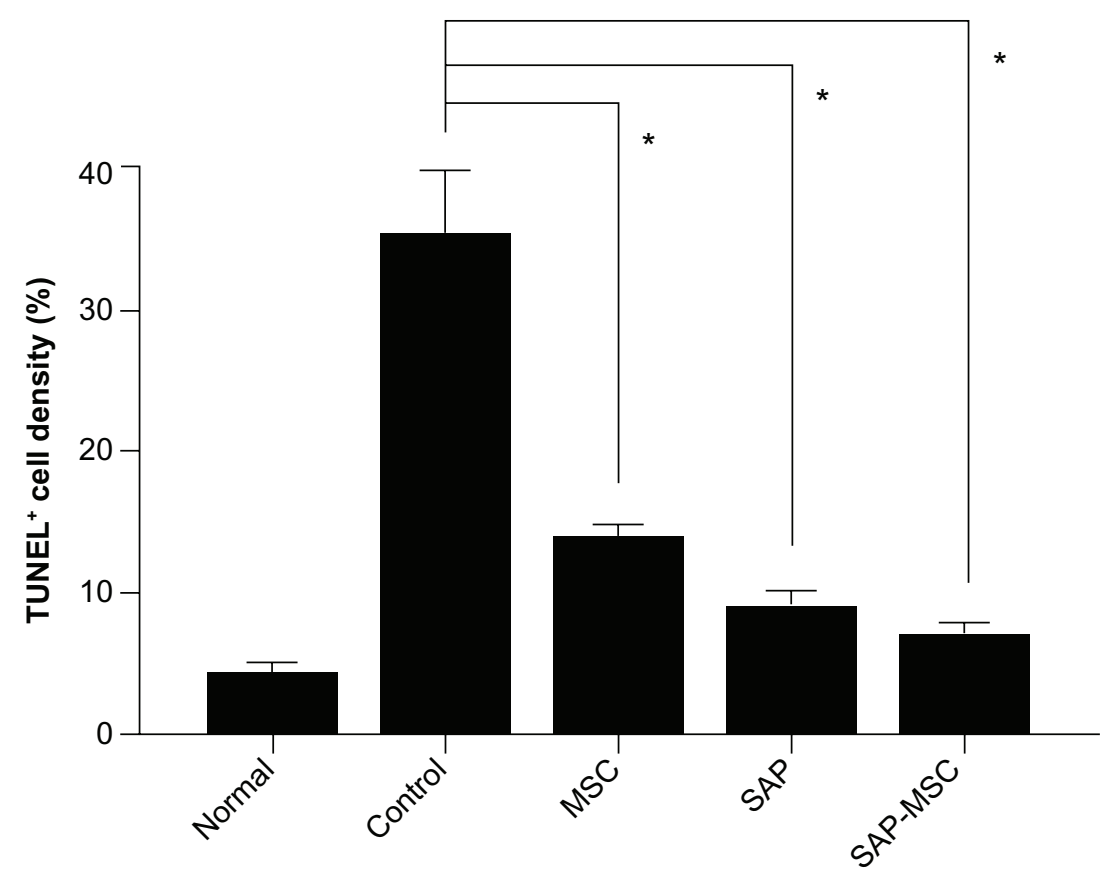

Figure 5 Apoptosis of chondrocytes in three rats from each group was detected by the DeadEnd Fluorometric TUNEL system. A significant difference of chondrocyte apoptosis between the control group and other groups was found (means \pm standard error of mean). $* P$-value is less than 0.05 .

Abbreviations: TUNEL, terminal deoxynucleotidyl transferase deoxyuridine triphosphate nick-end labeling; MSC, mesenchymal stem cell; SAP, self-assembled peptide.
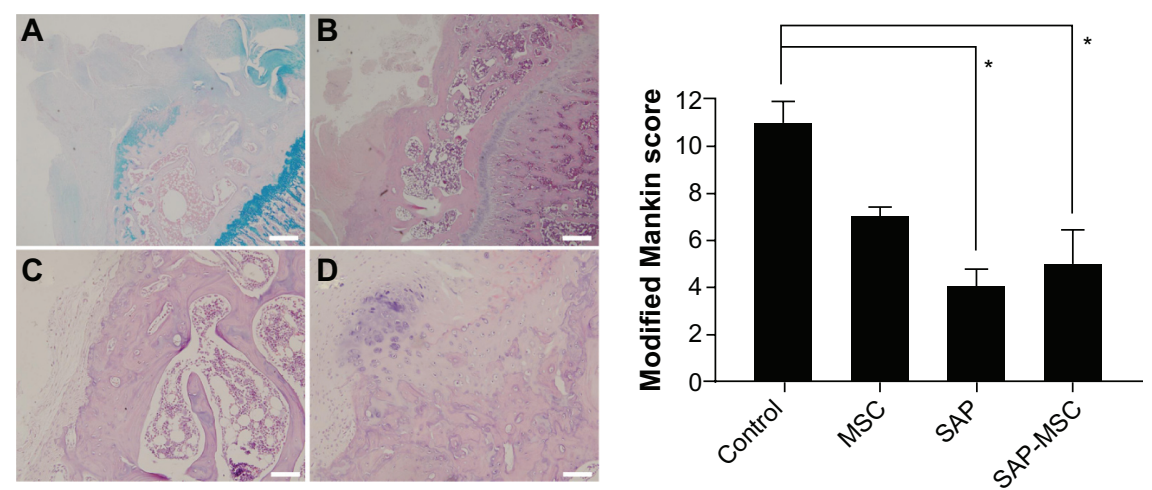

Figure 6 (A-D) Representative figures (magnification ratio 200 $\times$ ) are presented, and modified Mankin scores in the control ( $n=5)$, MSC $(n=6)$, SAP ( $=6$ ), and SAP-MSC ( $=6$ ) groups are shown as means \pm standard error of mean.

Notes: The scores in the SAP and SAP-MSC groups were significantly lower than that in the control group. From the left upper quadrant, figures show reduction in Alcian blue staining $(\mathbf{A})$, destroyed cartilage structures (B), destroyed tidemark $(\mathbf{C})$, and clusters of cartilage cells (D). Scale bar $50 \mu \mathrm{m}$. ${ }^{* P}$-value is less than 0.05 .

Abbreviations: MSC, mesenchymal stem cell; SAP, self-assembled peptide.
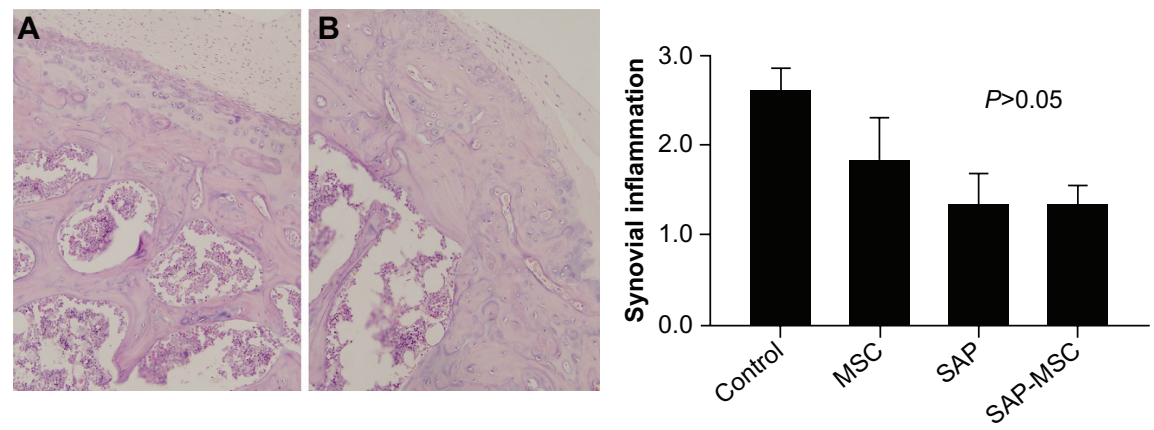

Figure 7 Representative figures (magnification ratio 200x) were presented for thickened synovial membrane infiltration of inflammatory cells in the control group (A) and reduced changes in the SAP-MSC group (B). Synovial inflammation scores in the control $(n=5)$, MSC $(n=6)$, SAP $(n=6)$, and SAP-MSC $(n=6)$ groups are shown as means \pm standard error of mean.

Abbreviations: MSC, mesenchymal stem cell; SAP, self-assembled peptide. 

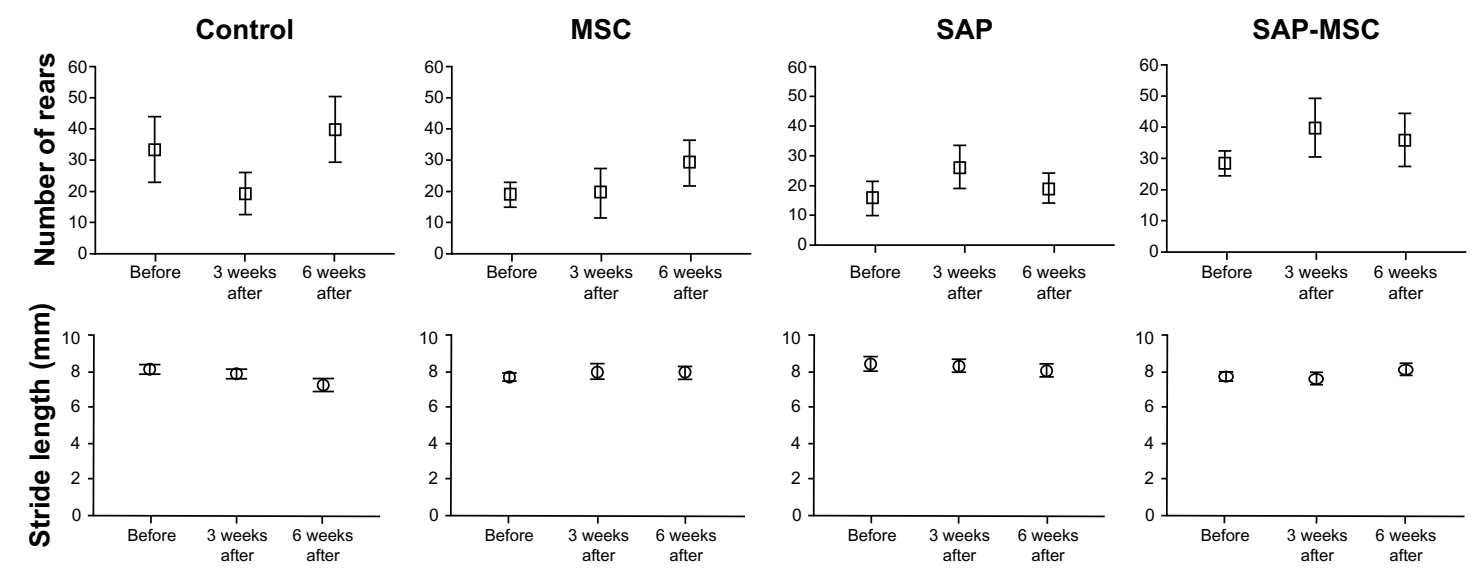

Figure 8 Behavioral results before, 3 weeks after, and 6 weeks after the injection were described in all groups (five rats in the control group and six rats in other groups). There was neither group nor time difference in the number of attempted rears ( $P=0.07 \mathrm{I}$ in time and $P=0.32 \mathrm{I}$ in group) or maximum stride length ( $P=0.537$ in time and $P=0.188$ in group).

Abbreviations: MSC, mesenchymal stem cell; SAP, self-assembled peptide.

Interestingly, MSCs by themselves did not show any therapeutic efficacy on the histology of OA progression. This may be explained by the fact that MSCs without an appropriate scaffold have limitations in their efficacy. ${ }^{6}$ Also, with regard to SAP by itself, it could be thought that the nanofibrous structure of SAP offered 3-D microenvironments to the cells. SAP can support cell attachment, migration, and differentiation of a variety of cells by providing a suitable microenvironment for cells to adhere to. ${ }^{33,34}$ Yoshimi et al reported that MSCs maintained their own potential by increasing attachment and survival rates of transplanted cells in the 3-D microenvironment by SAP and promoting tissue regeneration. ${ }^{35}$ Therefore, SAP provided 3-D microenvironments within the OA sites, which promoted remodeling of the cartilage and attaching surrounding cells as well as MSCs.

From the results of the biotin analysis, we were able to show that SAP stayed in the joint cavity for 6 weeks after the injection. This shows promise, as previous studies have shown that arthritic changes in SD rats develop within 6 weeks after the resection of the anterior cruciate ligament and medial meniscus. ${ }^{36}$ Thus, this persistence of SAP at 6 weeks postinjection in SD rats is enough time to show the effect of SAP or SAP-MSC on the progression of arthritis. We did not study the status of MSCs and SAP-MSC in the joint cavity using cell markers, but considering that injected MSCs were still detected at 8 weeks in the rat joint cavity in a previous study, ${ }^{37}$ we believe our MSCs and SAP-MSC would have been present in the joint cavity 6 weeks after the injection.

Immunofluorescent staining revealed the SAP, MSC, and SAP-MSC groups decreased expression of caspase- 8 and TIMP-1. Caspase- 8 was adopted as a parameter of chondrocyte apoptosis, MMP-9 as a parameter of extracellular matrix breakdown, and TIMP-1 as an inhibitor of MMP-9 during the progression of OA. ${ }^{38-40}$ Moreover, our results from the TUNEL assay provided evidence that supported the inhibition of apoptosis in the SAP, MSC, and SAP-MSC groups. This suggests that both SAP and MSCs have a function in protecting chondrocytes from apoptotic pathways. The inhibition of cell apoptosis is consistent with results from a previous study ${ }^{41}$ that revealed the cytoprotective effect of MSCs in SAP scaffolds.

MSCs alone showed significant decrease of chondrocyte apoptosis, but not in histologic grade compared to the negative control. The disagreement between these results can be attributed in part to additional mechanisms of OA progression that supersede chondrocyte apoptosis and the histologic findings. This notion is supported by many recent publications that document the significance of subchondral bone and synovial membrane changes in relation to the progression of OA. ${ }^{2,36,42,43}$

In contrast to a previous study by McErlain et al, ${ }^{44}$ in which they noted decreased subchondral bone mineral density in an OA rat model, our OA rat model showed that subchondral bone mineral density was increased. This might be due to different ages of rats used in the study and different methods to produce the OA model. McErlain et al used 3-week-old rats and performed transection of the anterior cruciate ligament with partial medial meniscectomy, while our model was created using 12-week-old rats and added transection of the medial collateral ligament to generate a more severe model of OA in terms of increased bone mineral density. Considering that late-stage OA elevates markers for bone formation ${ }^{36}$ and involves an increase in subchondral 
bone density, ${ }^{45}$ this result is plausible. The SAP-MSC group showed attenuation of an increase in subchondral bone density compared to the control group, which means that SAP-MSC shows positive subchondral bone turnover in the OA rat model.

Decreased immunofluorescent staining of TIMP-1 in the SAP-MSC group also supports the positive effect of SAPMSCs on subchondral bone turnover, as this molecule has been reported to be upregulated in OA subchondral bone. ${ }^{4}$ The injection of MSCs alone was not as effective as the injection of SAP-combined MSCs. This is postulated to be a result of inadequate regenerative action of undifferentiated MSCs. Without an adequate microenvironment to enhance the chondrogenesis of MSCs, the MSCs could decline in their cartilage-regeneration abilities, thus having a smaller contribution to the delay of OA progression. This result was consistent with a previous study that revealed that an intraarticular injection of properly differentiated bone marrowderived MSCs decreased bone mineral density and delayed progression of OA. ${ }^{46}$

Although not statistically significant, IL-1 $\beta$ levels and synovial inflammation scores were lower in the SAP and SAP-MSC groups than in the MSC group. In general, the SAP group was the only group that had a large decrease of IL-1 $\beta$ and synovial inflammation score over the control. This suggests an ability of SAPs to attenuate the immune response by anti-inflammatory properties, but appears to be negated by the addition of MSCs. Paradoxically, MSC and SAP-MSC injections slightly increased IL-1 $\beta$ levels over the control in our study. We surmise that this was due to an immune response generated by the use of allogenic MSCs, which might cause the increase of IL- $1 \beta .{ }^{47}$ However, we could not use autogenic MSCs from the bone marrow because of the small size of SD rats. TNF- $\alpha$, the other minor proinflammatory cytokine in OA, was not detected in our study, which might be due to its low level in OA articular tissue. ${ }^{48}$

We found no significant difference between groups from the behavioral tests in our study. This can be explained, because the number of attempted rears and maximum stride length of OA-induced animals are also affected by the pain and decreased proprioception evoked by OA. ${ }^{32}$ Neither SAP nor MSCs are likely to ameliorate pain or improve proprioception, according to our study. Although SAP decreased the level of a typical proinflammatory cytokine, IL- $\beta$, in our study, it might be insufficient to improve the activity level of rats with OA.

In this study, we did not investigate the fate of injected MSCs. Even though several studies were conducted on the effect of SAP on MSCs in in vitro studies, ${ }^{49-51}$ the fate of
MSCs injected into the joint cavity will be different according to the microenvironments, as stem cells have high susceptibility to diverse microenvironments, including mechanical strain, shear stress, and cell-cell interaction, and will show altered differentiation and paracrine effects. ${ }^{52,53}$ Wang $^{54}$ suggested the migration of injected MSCs from the injection site to the cartilage defect through the evidence of Prussian blue-positive and bromodeoxyuridine-labeled cells entering into the defect, which can be applied to our study. Further study investigating the fate of MSCs through in vivo tracking may suggest a molecular basis to support the results of our study.

\section{Conclusion}

In this study, we showed that MSCs encapsulated in SAP have several desirable properties that decelerate the progression of cartilage destruction in OA in a rat knee model. The mechanism for this effect appears to be due to the prevention of chondrocyte apoptosis, alteration of subchondral bone mineral density, a reduction trend of inflammation due to SAPs, and a potential chondrogenic mechanism for tissue regeneration supported by increased glycosaminoglycan synthesis. Although preliminary in nature, these findings suggest a role for SAP-MSC complexes as disease-modifying agents for the treatment of $\mathrm{OA}$.

\section{Acknowledgments}

This study was supported by the Korea Institute of Science and Technology Institutional Program (2E22710 and 2E23720) and a Samsung Medical Center Grant (SMR112041). DH Kim thanks the Department of Bioengineering at the University of Washington for the new faculty startup fund.

\section{Disclosure}

The authors report no conflicts of interest in this work.

\section{References}

1. Goldring SR, Goldring MB. Clinical aspects, pathology and pathophysiology of osteoarthritis. J Musculoskelet Neuronal Interact. 2006;6(4): 376-378.

2. Scanzello CR, Goldring SR. The role of synovitis in osteoarthritis pathogenesis. Bone. 2012;51(2):249-257.

3. Hugle T, Geurts J, Nüesch C, Müller-Gerbl M, Valderrabano V. Aging and osteoarthritis: an inevitable encounter? J Aging Res. 2012;2012: 950192.

4. Hulejová H, Baresová V, Klézl Z, Polanská M, Adam M, Senolt L. Increased level of cytokines and matrix metalloproteinases in osteoarthritic subchondral bone. Cytokine. 2007;38(3):151-156.

5. Zamli Z, Sharif M. Chondrocyte apoptosis: a cause or consequence of osteoarthritis? Int J Rheum Dis. 2011;14(2):159-166.

6. Dhinsa BS, Adesida AB. Current clinical therapies for cartilage repair, their limitation and the role of stem cells. Curr Stem Cell Res Ther. 2012; 7(2):143-148. 
7. Kapoor M, Martel-Pelletier J, Lajeunesse D, Pelletier JP, Fahmi H. Role of proinflammatory cytokines in the pathophysiology of osteoarthritis. Nat Rev Rheumatol. 2011;7(1):33-42.

8. van den Berg WB. Osteoarthritis year 2010 in review: pathomechanisms. Osteoarthritis Cartilage. 2011;19(4):338-341.

9. Wang CY, Chen LL, Kuo PY, Chang JL, Wang YJ, Hung SC. Apoptosis in chondrogenesis of human mesenchymal stem cells: effect of serum and medium supplements. Apoptosis. 2010;15(4):439-449.

10. Koga H, Engebretsen L, Brinchmann JE, Muneta T, Sekiya I. Mesenchymal stem cell-based therapy for cartilage repair: a review. Knee Surg Sports Traumatol Arthrosc. 2009;17(11):1289-1297.

11. Roberts S, Genever P, McCaskie A, De Bari C. Prospects of stem cell therapy in osteoarthritis. Regen Med. 2011;6(3):351-366.

12. MacFarlane RJ, Graham SM, Davies PS, et al. Anti-inflammatory role and immunomodulation of mesenchymal stem cells in systemic joint diseases: potential for treatment. Expert Opin Ther Targets. 2013; 17(3):243-254.

13. Branco MC, Schneider JP. Self-assembling materials for therapeutic delivery. Acta Biomater. 2009;5(3):817-831.

14. Zhang S. Designer self-assembling peptide nanofiber scaffolds for study of 3-D cell biology and beyond. Adv Cancer Res. 2008;99: 335-362.

15. Zhang S, Gelain F, Zhao X. Designer self-assembling peptide nanofiber scaffolds for 3D tissue cell cultures. Semin Cancer Biol. 2005;15(5): 413-420.

16. Narmoneva DA, Oni O, Sieminski AL, et al. Self-assembling short oligopeptides and the promotion of angiogenesis. Biomaterials. 2005; 26(23):4837-4846.

17. Webber MJ, Kessler JA, Stupp SI. Emerging peptide nanomedicine to regenerate tissues and organs. J Intern Med. 2010;267(1):71-88.

18. Horii A, Wang X, Gelain F, Zhang S. Biological designer selfassembling peptide nanofiber scaffolds significantly enhance osteoblast proliferation, differentiation and 3-D migration. PLoS One. 2007;2(2):e190.

19. Kisiday J, Jin M, Kurz B, et al. Self-assembling peptide hydrogel fosters chondrocyte extracellular matrix production and cell division: implications for cartilage tissue repair. Proc Natl Acad Sci U S A 2002;99(15):9996-10001.

20. Kopesky PW, Vanderploeg EJ, Sandy JS, Kurz B, Grodzinsky AJ. Self-assembling peptide hydrogels modulate in vitro chondrogenesis of bovine bone marrow stromal cells. Tissue Eng Part A. 2010;16(2): 465-477.

21. Erickson IE, Huang AH, Chung C, Li RT, Burdick JA, Mauck RL. Differential maturation and structure-function relationships in mesenchymal stem cell- and chondrocyte-seeded hydrogels. Tissue Eng Part A. 2009;15(5):1041-1052.

22. Kisiday JD, Kopesky PW, Evans CH, Grodzinsky AJ, McIlwraith CW, Frisbie DD. Evaluation of adult equine bone marrow- and adiposederived progenitor cell chondrogenesis in hydrogel cultures. $J$ Orthop Res. 2008;26(3):322-331.

23. Miller RE, Grodzinsky AJ, Vanderploeg EJ, et al. Effect of selfassembling peptide, chondrogenic factors, and bone marrow-derived stromal cells on osteochondral repair. Osteoarthritis Cartilage. 2010;18(12):1608-1619.

24. Jung Y, Kim SH, Kim YH. The effects of dynamic and threedimensional environments on chondrogenic differentiation of bone marrow stromal cells. Biomed Mater. 2009;4(5):055009.

25. Kim JH, Jung Y, Kim SH, et al. The enhancement of mature vessel formation and cardiac function in infarcted hearts using dual growth factor delivery with self-assembling peptides. Biomaterials. 2011;32(26): 6080-6088.

26. Herr MM, Fries KM, Upton LG, Edsberg LE. Potential biomarkers of temporomandibular joint disorders. J Oral Maxillofac Surg. 2011;69(1): 41-47.

27. Barton NJ, Stevens DA, Hughes JP, et al. Demonstration of a novel technique to quantitatively assess inflammatory mediators and cells in rat knee joints. J Inflamm (Lond). 2007;4:13.
28. Chan WP, Lang P, Stevens MP, et al. Osteoarthritis of the knee: comparison of radiography, CT and MR imaging to assess extent and severity. AJR Am J Roentgenol. 1991;157(4):799-806.

29. Appleton CT, McErlain DD, Henry JL, Holdsworth DW, Beier F. Molecular and histological analysis of a new rat model of experimental knee osteoarthritis. Ann NY Acad Sci. 2007;1117:165-174.

30. Kuroki H, Nakagawa Y, Mori K, et al. Acoustic stiffness and change in plug cartilage over time after autologous osteochondral grafting: correlation between ultrasound signal intensity and histological score in a rabbit model. Arthritis Res Ther. 2004;6(6):R492-R504.

31. Mapp PI, Sagar DR, Ashraf S, et al. Differences in structural and pain phenotypes in the sodium monoiodoacetate and meniscal transection models of osteoarthritis. Osteoarthritis Cartilage. 2013;21(9): 1336-1345.

32. Nagase H, Kumakura S, Shimada K. Establishment of a novel objective and quantitative method to assess pain-related behavior in monosodium iodoacetate-induced osteoarthritis in rat knee. J Pharmacol Toxicol Methods. 2012;65(1):29-36.

33. Ellis-Behnke RG, Liang YX, You SW, et al. Nano neuro knitting: peptide nanofiber scaffold for brain repair and axon regeneration with functional return of vision. Proc Natl Acad Sci U S A. 2006;103(13): 5054-5059.

34. Zhang S, Holmes TC, DiPersio CM, Hynes RO, Su X, Rich A. Self-complementary oligopeptide matrices support mammalian cell attachment. Biomaterials. 1995;16(18):1385-1393.

35. Yoshimi R, Yamada Y, Ito K, et al. Self-assembling peptide nanofiber scaffolds, platelet-rich plasma, and mesenchymal stem cells for injectable bone regeneration with tissue engineering. J Craniofac Surg. 2009;20(5):1523-1530.

36. Pickarski M, Hayami T, Zhuo Y, Duong le T. Molecular changes in articular cartilage and subchondral bone in the rat anterior cruciate ligament transection and meniscectomized models of osteoarthritis. BMC Musculoskelet Disord. 2011;12:197.

37. Horie M, Choi H, Lee RH, et al. Intra-articular injection of human mesenchymal stem cells (MSCs) promote rat meniscal regeneration by being activated to express Indian hedgehog that enhances expression of type II collagen. Osteoarthritis Cartilage. 2012;20(10): 1197-1207.

38. Bian Q, Wang YJ, Liu SF, Li YP. Osteoarthritis: genetic factors, animal models, mechanisms, and therapies. Front Biosci (Elite Ed). 2012;4: 74-100.

39. Mistry D, Oue Y, Chambers MG, Kayser MV, Mason RM. Chondrocyte death during murine osteoarthritis. Osteoarthritis Cartilage. 2004;12(2): $131-141$.

40. Tanaka S, Hamanishi C, Kikuchi H, Fukuda K. Factors related to degradation of articular cartilage in osteoarthritis: a review. Semin Arthritis Rheum. 1998;27(6):392-399.

41. Guo HD, Cui GH, Wang HJ, Tan YZ. Transplantation of marrowderived cardiac stem cells carried in designer self-assembling peptide nanofibers improves cardiac function after myocardial infarction. Biochem Biophys Res Commun. 2010;399(1):42-48.

42. Honsawek S, Chayanupatkul M. Correlation of plasma and synovial fluid adiponectin with knee osteoarthritis severity. Arch Med Res. 2010; 41(8):593-598.

43. Aigner T, Sachse A, Gebhard PM, Roach HI. Osteoarthritis: pathobiologytargets and ways for therapeutic intervention. Adv Drug Deliv Rev. 2006;58(2):128-149.

44. McErlain DD, Appleton CT, Litchfield RB, et al. Study of subchondral bone adaptations in a rodent surgical model of OA using in vivo micro-computed tomography. Osteoarthritis Cartilage. 2008;16(4): 458-469.

45. Burr DB, Gallant MA. Bone remodelling in osteoarthritis. Nat Rev Rheumatol. 2012;8(11):665-673.

46. Chen K, Man C, Zhang B, Hu J, Zhu SS. Effect of in vitro chondrogenic differentiation of autologous mesenchymal stem cells on cartilage and subchondral cancellous bone repair in osteoarthritis of temporomandibular joint. Int J Oral Maxillofac Surg. 2013;42(2):240-248. 
47. Imanishi Y, Saito A, Komoda H, et al. Allogenic mesenchymal stem cell transplantation has a therapeutic effect in acute myocardial infarction in rats. J Mol Cell Cardiol. 2008;44(4):662-671.

48. Fernandes JC, Martel-Pelletier J, Pelletier JP. The role of cytokines in osteoarthritis pathophysiology. Biorheology. 2002;39(1-2):237-246.

49. Stevenson MD, Piristine H, Hogrebe NJ, et al. A self-assembling peptide matrix used to control stiffness and binding site density supports the formation of microvascular networks in three dimensions. Acta Biomater. 2013;9(8):7651-7661.

50. Chen J, Shi ZD, Ji X, et al. Enhanced osteogenesis of human mesenchymal stem cells by periodic heat shock in self-assembling peptide hydrogel. Tissue Eng Part A. 2013;19(5-6):716-728.

51. Webber MJ, Han X, Murthy SN, Rajangam K, Stupp SI, Lomasney JW. Capturing the stem cell paracrine effect using heparin-presenting nanofibres to treat cardiovascular diseases. J Tissue Eng Regen Med. 2010;4(8):600-610.
52. Kshitiz, Park J, Kim P, et al. Control of stem cell fate and function by engineering physical microenvironments. Integr Biol (Camb). 2012; 4(9):1008-1018.

53. Kshitiz, Kim DH, Beebe DJ, Levchenko A. Micro- and nanoengineering for stem cell biology: the promise with a caution. Trends Biotechnol. 2011;29(8):399-408.

54. Wang YX. Comment on Jing et al. original article "In vivo MR imaging tracking of magnetic iron oxide nanoparticle labeled, engineered, autologous bone marrow mesenchymal stem cells following intraarticular injection." Joint Bone Spine. 2009;76(1):118-119; author reply $119-120$. 


\section{Supplementary materials}

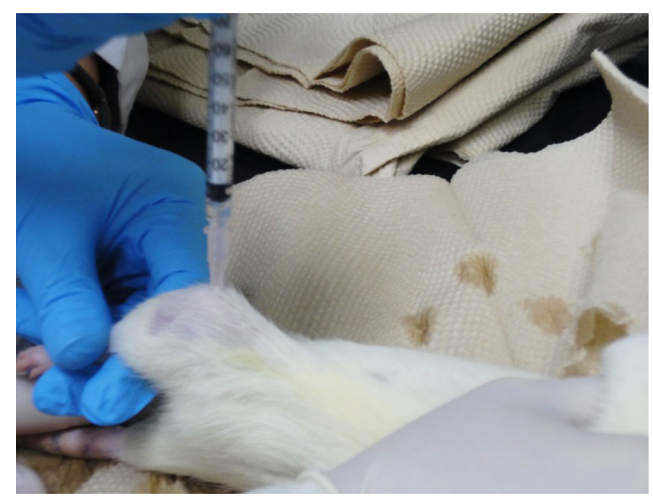

Figure SI Intra-articular injection $(0.2 \mathrm{~mL})$ of SAP, MSC, and SAP-MSC was administered directly into the articular cavity. After palpating the patella with the knee bent, a 26-gauge needle was inserted about $5 \mathrm{~mm}$ above the upper margin of the patella. With verification of no soft-tissue swelling, each compound was injected directly into the articular cavity.

Abbreviations: MSC, mesenchymal stem cell; SAP, self-assembled peptide.

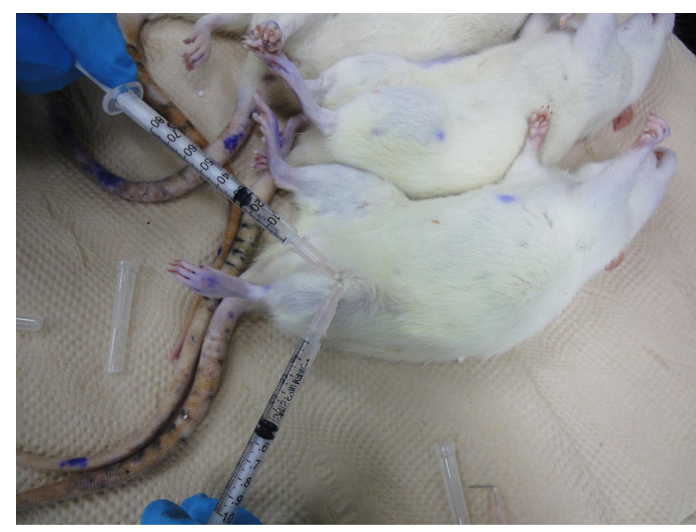

Figure S2 Synovial fluid extraction. Needles of two syringes were inserted into an articular cavity of killed animals. Phosphate-buffered saline was infused into the articular cavity and constantly withdrawn by the other syringe. The rate of infusion and withdrawal was manually but carefully controlled in order to prevent any leakage of synovial fluid into the surrounding soft tissue.

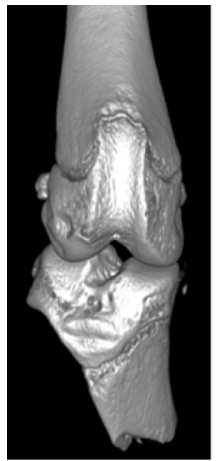

Grade $1 \mathrm{OA}$

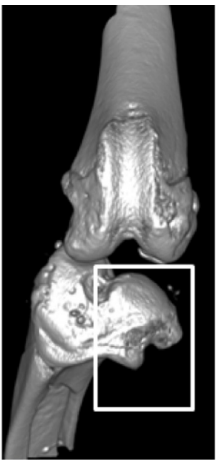

Grade 2 OA (bony spur)

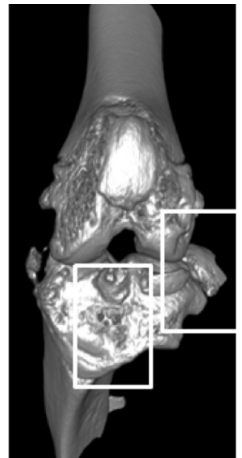

Grade 3 OA (bony spur with focal defect)

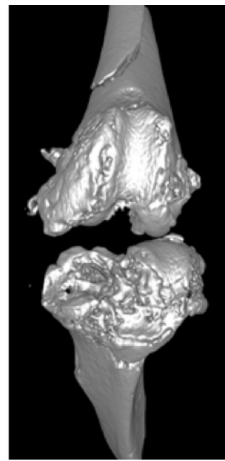

Grade 4 OA (bony spur with general defect)

Figure S3 Osteoarthritis (OA) grade was rated using micro-computed tomography (CT). All grades were rated by a blinded subject.

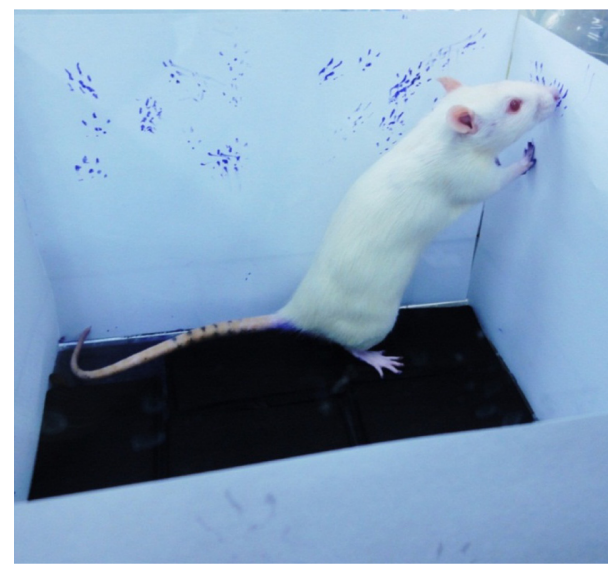

Figure S4 An open-field acrylic box with dimensions of $30 \times 30 \times 30 \mathrm{~cm}^{3}$ was placed in a room with minimum noise. The bottom consisted of several foam stamp pads. The rats got their paws covered in ink and left footprints on the paper when they stood on their hind limbs and touched the walls of the box with their forelimbs. 
A

$\because$ $\therefore$ $\because \because \because \quad \because \cdots$ $\because \because$,
C .

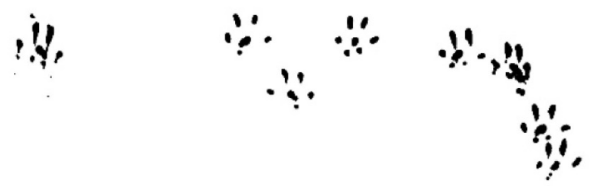

D

\section{B}

$\because \because$ $\because 1$.

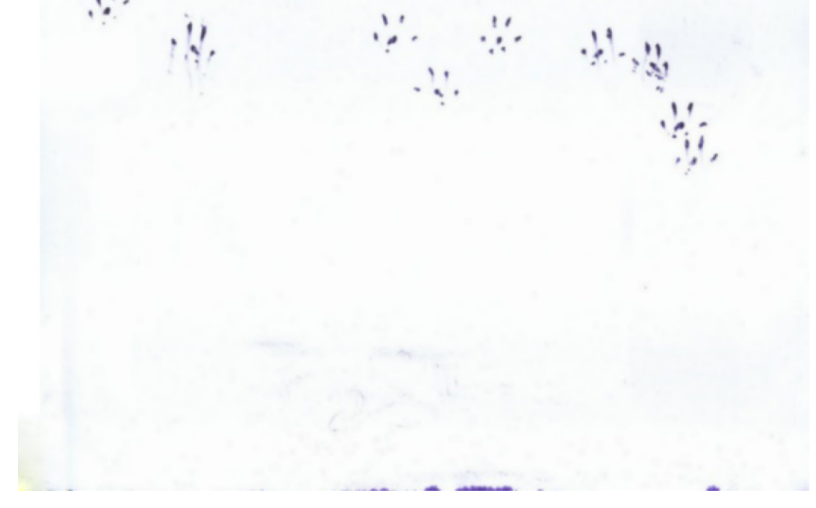

2251x1651 pixels; 8-bit (inverting LUT), 3.5MB

$\because \cdot$

i\$,

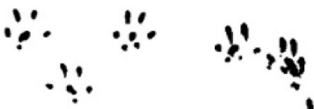
$\because \because \%$

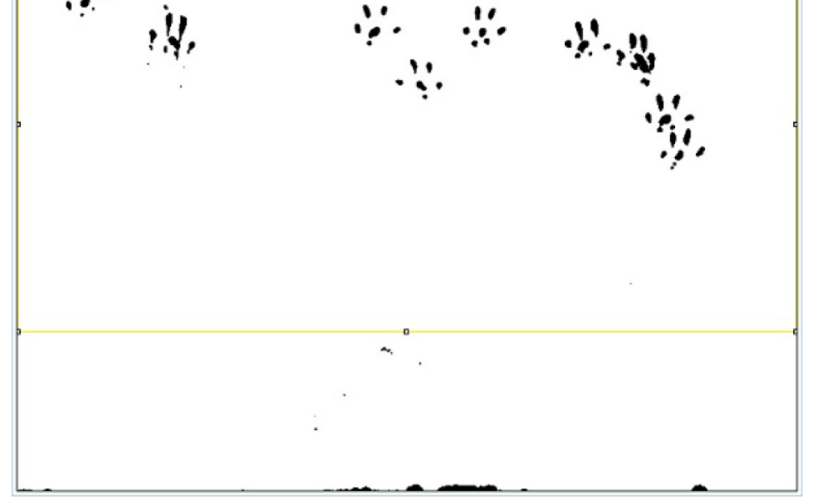

Figure S5 (A-D) Estimating the number of rears attempted with ImageJ software. (A) The papers containing rat footprints are scanned and saved as image files. (B) The saved image files were digitally smoothed by using the "Smooth" function under the "Process" menu in Imagej. (C) The images were changed to 8-bit images by selecting "Type" and "8-bit" under the "Image" menu. The threshold level of the images was set to 230 for binary image acquisition by clicking "Adjust" and "Threshold" under the "Image" menu. (D) The number of distinct particles above $5 \mathrm{~cm}$ from the bottom of the image was counted by first making rectangular selections in the images and using "Analyze particles" under the "Analyze" menu. The number of rears was estimated by dividing the number of particles by 14.

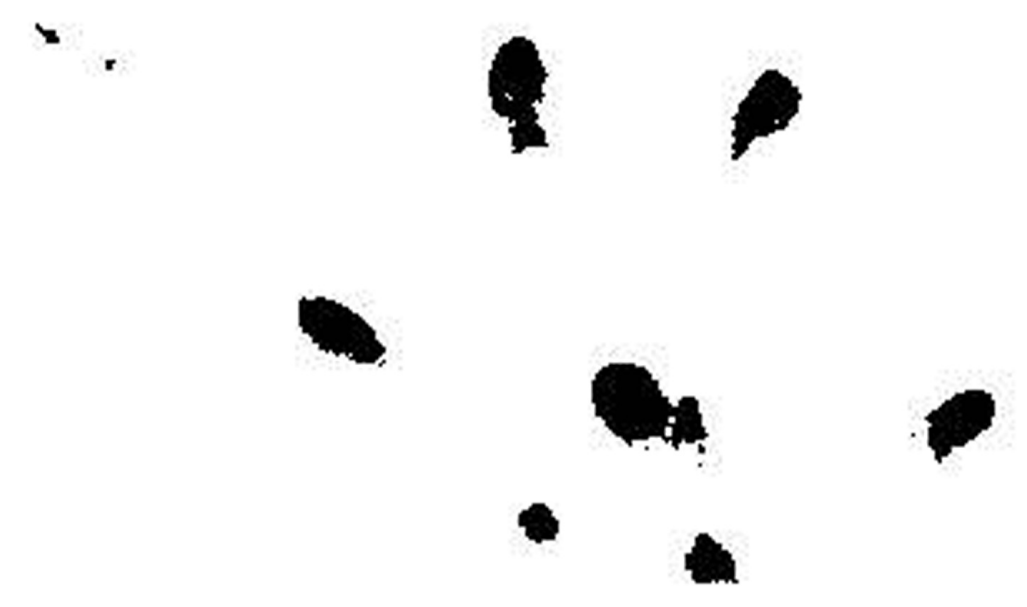

Figure S6 Sample footprints of rodents. Procedure the same as Hasler et al.' 


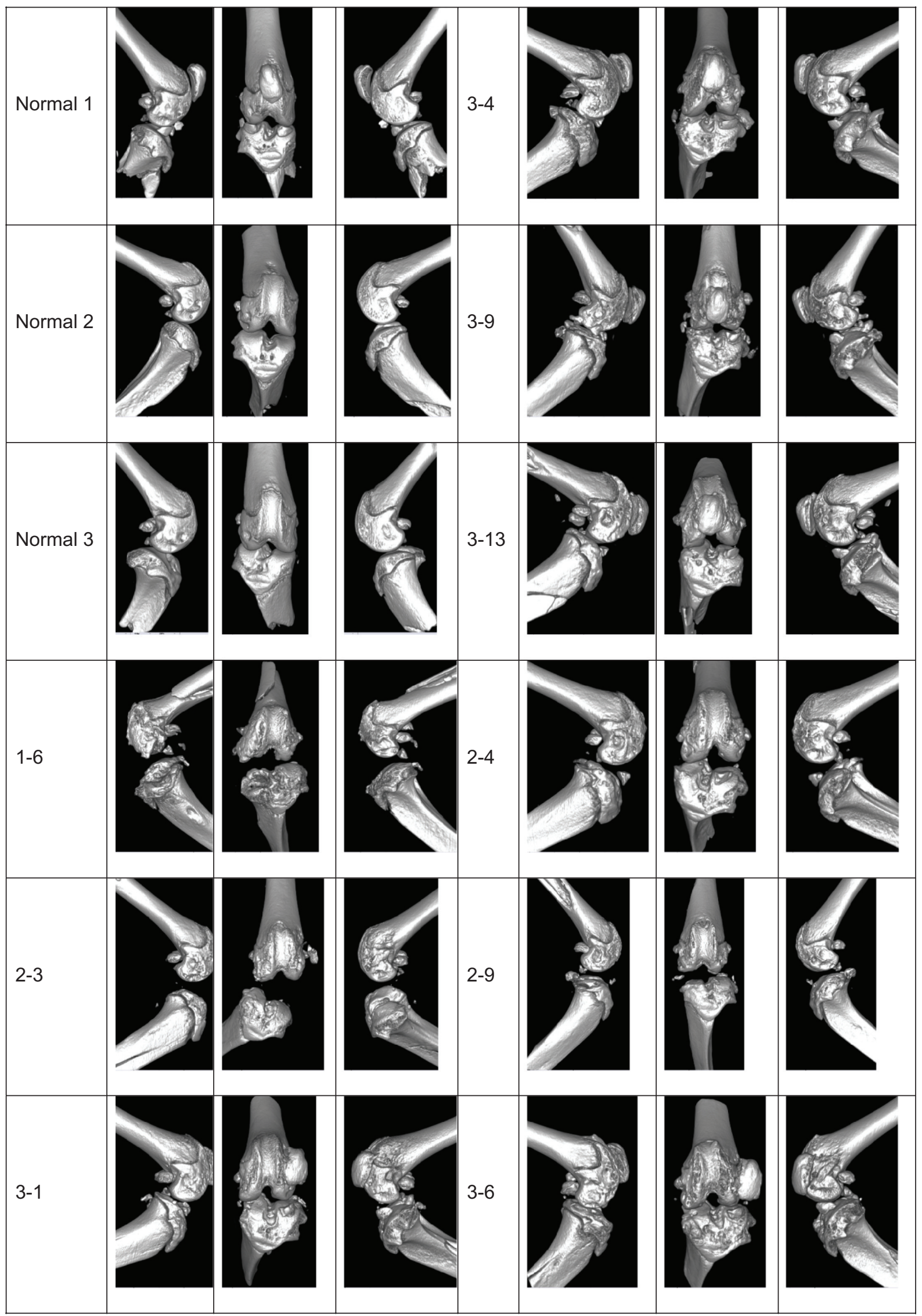

Figure S7 (Continued) 


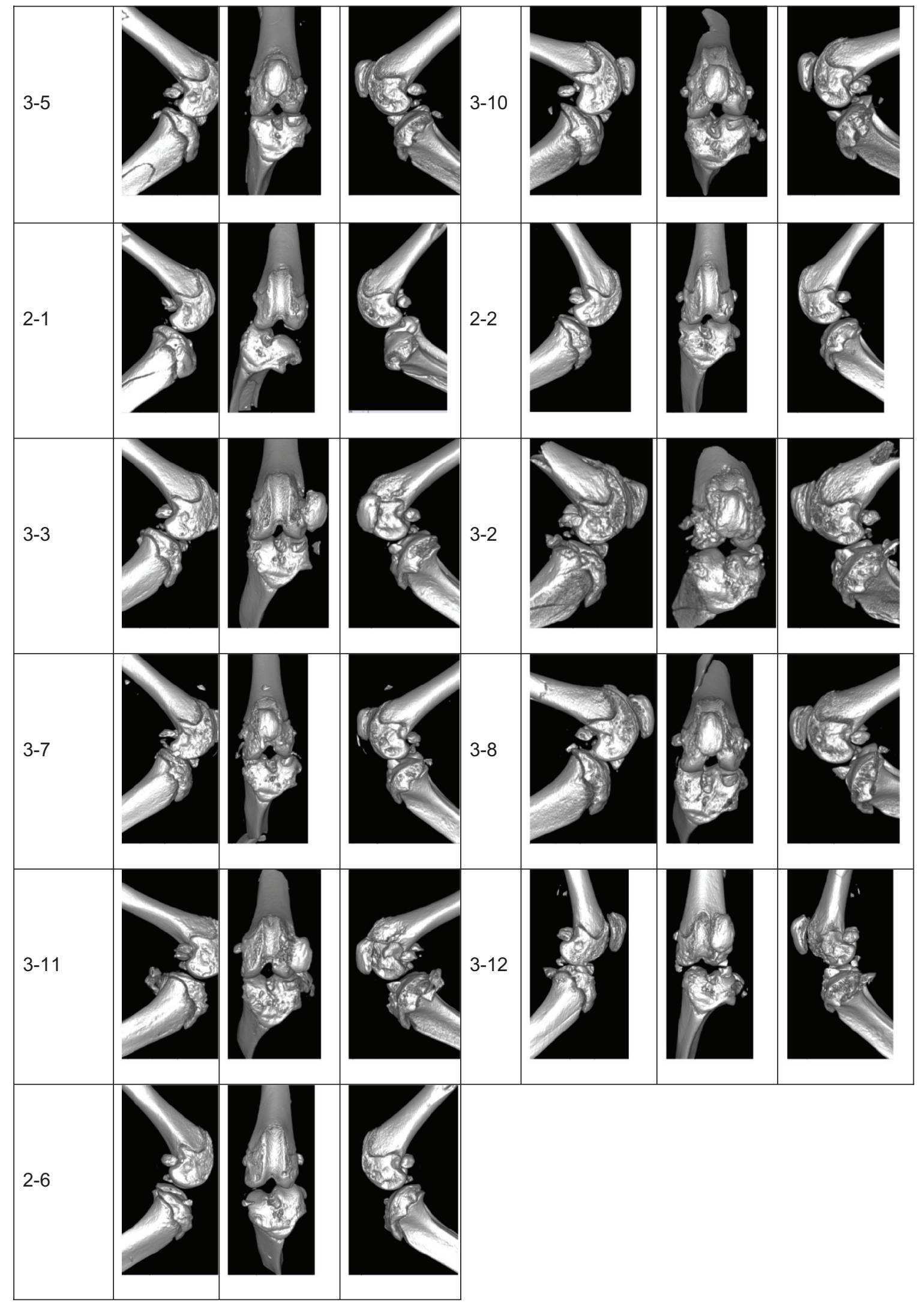

Figure S7 Micro-computed tomography images of rat knee joints. The Inveon system was used. The scanned images were exported and analyzed using Inveon Research Workplace. Regions of interests were drawn on trabecular bones for three-dimensional visualization. 


\section{Reference}

1. Hasler N, Klette R, Rosenhahn B, Agnew W. Footprint recognition of rodents and insects. Communication and Information Technology Research Technical Report 149, (2004). The University of Auckland. 2004. Available from http://citr.auckland.ac.nz/techreports/2004/CITRTR-149.pdf. Accessed November 2, 2013.

International Journal of Nanomedicine

\section{Publish your work in this journal}

The International Journal of Nanomedicine is an international, peerreviewed journal focusing on the application of nanotechnology in diagnostics, therapeutics, and drug delivery systems throughou the biomedical field. This journal is indexed on PubMed Central, MedLine, CAS, SciSearch $®$, Current Contents ${ } /$ Clinical Medicine,
Journal Citation Reports/Science Edition, EMBase, Scopus and the Elsevier Bibliographic databases. The manuscript management system is completely online and includes a very quick and fair peer-review system, which is all easy to use. Visit http://www.dovepress.com/ testimonials.php to read real quotes from published authors.

Submit your manuscript here: http://www.dovepress.com/international-journal-of-nanomedicine-journal 